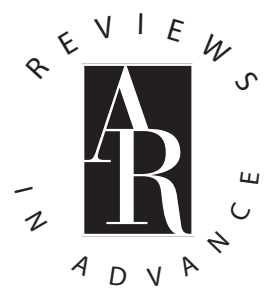

Review in Advance first posted online on 0 ctober 17, 2014. (Changes may still occur before final publication online and in print.)

\title{
Lessons From the RV144 Thai Phase III HIV-1 Vaccine Trial and the Search for Correlates of Protection
}

\author{
Jerome H. Kim, ${ }^{1}$ Jean-Louis Excler, ${ }^{1,2}$ \\ and Nelson L. Michael ${ }^{1}$
}

${ }^{1}$ US Military HIV Research Program, Walter Reed Army Institute of Research, Silver Spring, Maryland 20910; email: jkim@hivresearch.org, nmichael@hivresearch.org

${ }^{2}$ US Military HIV Research Program, Henry M. Jackson Foundation, Bethesda, Maryland 20817; email: jexcler@hivresearch.org

Annu. Rev. Med. 2015. 66:6.1-6.15

The Annual Review of Medicine is online at med.annualreviews.org

This article's doi:

10.1146/annurev-med-052912-123749

Copyright (c) 2015 by Annual Reviews. All rights reserved

\section{Keywords}

efficacy, correlates of risk, nonneutralizing antibody, neutralizing antibody, antibody-dependent cytotoxicity, envelope

\begin{abstract}
RV144 remains the only HIV-1 vaccine trial to demonstrate efficacy against HIV-1 acquisition. The prespecified analysis of immune correlates of risk showed that antibodies directed against the V1V2 region of gp120, in particular the IgG1 and IgG3 subclass mediating antibody-dependent cellmediated cytotoxicity, seem to play a predominant role in protection against HIV-1 acquisition and that plasma envelope (Env)-specific IgA antibodies were directly correlated with risk. RV144 and recent nonhuman primate challenge studies suggest that Env is essential, and perhaps sufficient, to induce protective antibody responses against mucosal HIV-1 acquisition. Follow-up clinical trials are ongoing to further dissect the immune responses elicited by the RV144 ALVAC-HIV and AIDSVAX ${ }^{\circledR}$ B/E regimen. The study of gp120 Env immunogens and immune correlates of risk has resulted in the development of improved antigens. Whether the RV144 immune correlates of risk will generalize to other populations vaccinated with similar immunogens with different modes and intensity of transmission remains to be demonstrated. Efficacy trials are now planned in heterosexual populations in southern Africa and men who have sex with men in Thailand.
\end{abstract}


IDU: injecting drug user

MSM: men who have sex with men

CoR: correlate(s) of risk

NAb: neutralizing antibody

bNAb: broadly neutralizing antibody

NHP: nonhuman primate

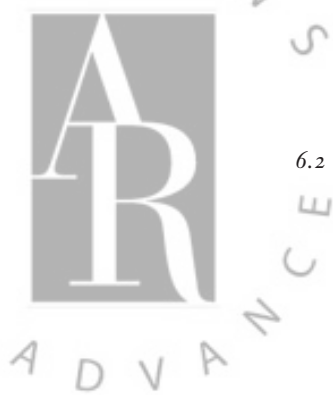

\section{INTRODUCTION}

According to UNAIDS, 35.3 million people were living with HIV-1 at the end of 2012 (1). Although the greatest burden of disease is present in sub-Saharan Africa (69\% of global HIV-1 infections), substantial and dynamic epidemics exist in Southeast Asia (2) and among persons in high-risk groups throughout the world. Remarkable progress has been achieved in slowing the spread of HIV-1 and preventing AIDS-related death in the setting of broad programs of prevention through effective condom use, circumcision, harm reduction in injecting drug users (IDUs), prevention of mother-to-child transmission, and availability of antiretroviral therapy (1). The use of a vaginal microbicide containing tenofovir conferred a 39\% reduction in infection (3), and oral pre-exposure prophylaxis has shown efficacy in reducing HIV-1 acquisition in men who have sex with men (MSM) (4), discordant couples (5), and IDUs (6), but not in African women (7). An effective HIV-1 vaccine would provide a critical and cost-effective addition to comprehensive programs of HIV-1 prevention (8).

The task of vaccine development is confounded by outstanding scientific challenges. The absence of a sterilizing host immune response, our limited understanding of a vaccine-induced correlate of risk (CoR), and imperfect predictive animal models mean that progress in HIV-1 vaccine development is limited to hypothesis testing in human efficacy trials, followed by the identification of potential CoR (9). The extraordinary sequence variation of HIV-1 (10) complicates the choice of immunogens for a vaccine (11). Infection and destruction of $\mathrm{CD}^{+}{ }^{+} \mathrm{T}$ helper cells undermine effective immune responses, and integration of $\mathrm{HIV}-1$ into $\mathrm{CD}^{+}{ }^{+} \mathrm{T}$ cells further facilitates viral persistence by incorporation into a long-lived, self-regenerating, $\mathrm{T}$ central memory pool (12). Neutralizing antibody (NAb) develops during the course of infection, and broadly neutralizing antibody (bNAb) develops in $20 \%$ of people within two years of infection, but the ability of HIV-1 to escape neutralization means that even persons with bNAbs eventually progress to AIDS and death $(13,14)$.

\section{WHAT ARE THE RELEVANT IMMUNE RESPONSES?}

Mechanistic and nonmechanistic (15) immune functions involved in protection against acquisition may differ by body compartments and be redundant (16). In the absence of curative innate and adaptive immune responses, empirically, one might consider NAb to be a critical component of protection, but early work showed that these responses were directed primarily at the variable and more exposed V3 loop. Moreover, evaluation of products generating type-specific NAb failed to show efficacy in Vax003 and Vax004. Given that infection of a host cell by HIV-1 results in integration, the ability of non-neutralizing antibodies to contribute to protection from acquisition has long been questioned. However, nonhuman primate (NHP) studies with simian immunodeficiency virus (SIV) suggest that protection from infection may be partially mediated by non-neutralizing antibody $(17,18)$, although it is important to validate animal models against human clinical trials, ideally in a prospective and coordinated fashion. Finally, in the absence of known or proven CoR, studies of HIV-infected persons, particularly those in the very early stages of infection and elite controllers (19), might provide insight into relevant immune mechanisms of control and inform vaccine design. It remains the case that CoR must be drawn from efficacy trials that, showing efficacy or not, might provide data on immune responses that correlate with reduced risk of HIV-1 infection.

\section{SUMMARY OF HIV-1 VACCINE EFFICACY TRIALS}

To date, four HIV-1 vaccine concepts have been tested in six efficacy trials (Table 1). AIDSVAX ${ }^{\circledR}$ $\mathrm{B} / \mathrm{B}$ ' is a bivalent vaccine containing the monomeric gp120s from the subtype B strains $\mathrm{MN}$ and

Kim • Excler • Michael 
Table 1 Human preventive HIV vaccine efficacy trials

\begin{tabular}{|c|c|c|c|c|c|c|}
\hline Study & Vaccines & Phase & Volunteers' risk & $\begin{array}{l}\text { HIV incidence } \\
\text { per } 100 \\
\text { person-years }\end{array}$ & Location & Result \\
\hline Vax004 & $\begin{array}{c}\text { AIDSVAX }^{\circledR} \text { B/B } \\
\text { gp120 in alum }\end{array}$ & III & $\begin{array}{l}\text { MSM and women at } \\
\text { high risk }\end{array}$ & $2.6 \%$ & $\begin{array}{l}\text { United } \\
\text { States, } \\
\text { Europe }\end{array}$ & No efficacy \\
\hline$\overline{\text { Vax003 }}$ & $\begin{array}{l}\text { AIDSVAX }^{\circledR} \text { B/E } \\
\text { gp120 in alum }\end{array}$ & III & Injecting drug users & $3.4 \%$ & Thailand & No efficacy \\
\hline $\begin{array}{l}\text { HVTN 502Step } \\
\text { trial }\end{array}$ & $\begin{array}{l}\text { MRKAd5 HIV-1 } \\
\text { gag/pol/nef B }\end{array}$ & $\mathrm{IIb}$ & $\begin{array}{l}\text { MSM and } \\
\text { heterosexual } \\
\text { women and men }\end{array}$ & $3.0 \%$ & $\begin{array}{r}\text { United } \\
\text { States }\end{array}$ & $\begin{array}{l}\text { No efficacy; transient } \\
\text { increased infection rate } \\
\text { in vaccinees }\end{array}$ \\
\hline RV144 & $\begin{array}{l}\text { ALVAC-HIV } \\
\text { vCP1521 and } \\
\text { AIDSVAX B/E } \\
\text { rgp120 in alum }\end{array}$ & III & $\begin{array}{l}\text { Community-risk } \\
\text { population }\end{array}$ & $0.28 \%$ & Thailand & $\begin{array}{l}31.2 \% \text { efficacy at } \\
42 \text { months, } 60 \% \text { at } \\
12 \text { months against HIV } \\
\text { acquisition. No effect } \\
\text { on plasma viral load } \\
\text { and CD4 count }\end{array}$ \\
\hline $\begin{array}{l}\text { HVTN } \\
\text { 503Phambili } \\
\text { trial }\end{array}$ & $\begin{array}{l}\text { MRKAd5 HIV-1 } \\
\text { gag/pol/nef B }\end{array}$ & $\mathrm{IIb}$ & $\begin{array}{l}\text { Heterosexual men } \\
\text { and women }\end{array}$ & $\begin{array}{l}3.7 \% \text { Placebos } \\
4.54 \% \\
\text { Vaccinees }\end{array}$ & $\begin{array}{l}\text { Republic } \\
\text { of } \\
\text { South } \\
\text { Africa }\end{array}$ & $\begin{array}{l}\text { No efficacy; increased } \\
H I V \text { infection rate in } \\
\text { vaccinees }\end{array}$ \\
\hline HVTN 505 & $\begin{array}{l}\text { DNA and rAd5 } \\
(\mathrm{A}, \mathrm{B}, \text { and } \mathrm{C})\end{array}$ & $\mathrm{IIb}$ & $\begin{array}{l}\text { MSM with } \\
\text { Ad5-specific } \\
\text { antibody titers } \\
<1: 18 \text { (negative) }\end{array}$ & $0.018 \%$ & $\begin{array}{r}\text { United } \\
\text { States }\end{array}$ & $\begin{array}{l}\text { Stopped for futility; no } \\
\text { efficacy on HIV } \\
\text { acquisition, plasma viral } \\
\text { load and CD4 count }\end{array}$ \\
\hline
\end{tabular}

GNE8 in alum. It protected chimpanzees from intravenous challenge (20,21), an effect possibly mediated by antibody against the V3 loop. The vaccine did not prevent HIV-1 acquisition, nor did it affect HIV-1 disease progression in MSM and high-risk women (22). High NAb levels against the HIV-1 MN variant were, however, significantly inversely correlated with HIV-1 infection risk whereas low levels against more-difficult-to-neutralize viruses failed to correlate, suggesting that level and breadth were not sufficient for protection (23). AIDSVAX ${ }^{\circledR} \mathrm{B} / \mathrm{E}$ is a bivalent vaccine containing the monomeric gp120s from the CCR5 tropic CRF01_AE strain CM244 (A244) and from subtype B MN. AIDSVAX ${ }^{\circledR} \mathrm{B} / \mathrm{E}$ conferred no efficacy in Thai IDUs (24). AIDSVAX ${ }^{\circledR}$ $\mathrm{B} / \mathrm{B}^{\prime}$ and AIDSVAX ${ }^{\circledR} \mathrm{B} / \mathrm{E}$ gp120s are each characterized by a deletion of 11 amino acids and the insertion of the Herpes simplex type $2 \mathrm{gD}$ protein at their $\mathrm{N}$ terminus. They were administered at the dose of $600 \mu \mathrm{g}(300 \mu \mathrm{g}$ of each gp120).

The Merck recombinant Ad5 gag/pol/nef vaccine was tested in the Step (HVTN 502) and Phambili (HVTN 503) trials. The Step trial, conducted in MSM and high-risk women in the Americas, Caribbean, and Australia, was stopped for futility $(25,26)$. A sieve analysis showed evidence of vaccine-elicited immune pressure on the founder virus, although no specific CD8 ${ }^{+}$ cytotoxic lymphocytes recognizing that epitope could be identified (27). Vaccinees with human leukocyte antigen alleles associated with HIV-1 control had a significantly lower mean viral load over time (28). The most highly conserved epitopes were detected at a lower frequency, suggesting that stronger responses to conserved sequences may be as important as breadth for protection (29). 
$\mathrm{VE}$ : vaccine efficacy

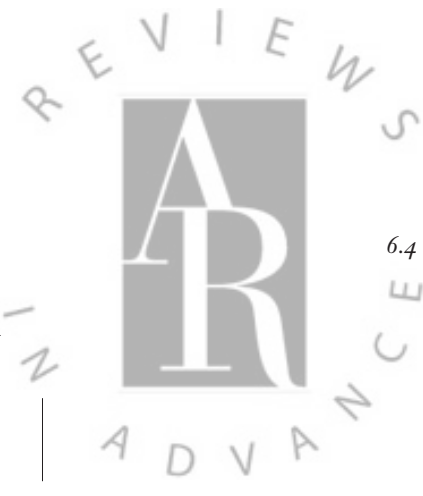

Phambili, conducted in sexually active heterosexuals in the Republic of South Africa, was stopped shortly after Step, during study enrollment, and subjects were unblinded (30). There appeared to be excess infection in the vaccine arms of both these studies, and the etiology of this effect is unknown; for Step (but not for Phambili), Ad5 serostatus and circumcision status appeared to be important covariates (31). The unblinded long-term follow-up of Phambili participants provided further evidence of excess infections, especially in heterosexual men, for which the underlying mechanisms remain unclear (32). The outcome of the Step trial was recapitulated in an Indian rhesus macaque study; animals vaccinated with a regimen similar to that employed in the Step trial were not protected against intrarectal SIVE660 (33) or penile SIVmac251 (34) challenges.

Recently, HVTN 505, which utilized a gag/pol/env subtype A/B/C DNA prime with a matched recombinant Ad5 (rAd5) boost in North American MSM, was stopped for futility (35). This primeboost vaccine regimen protected NHPs against a heterologous SIVsmE660 intrarectal challenge but not against SIVmac251 infection. However, low levels of NAb measured in peripheral blood mononuclear cells and an Env-specific $\mathrm{CD}_{4}^{+} \mathrm{T}$ cell response were associated with vaccine protection (36). Interestingly, a separate NHP trial of the same DNA/rAd5 regimen with E660 challenge demonstrated that the Env component was necessary and sufficient for protection (37). RV144, with a vaccine efficacy (VE) of $31.2 \%$, discussed below, is the only trial conducted in a lowincidence mostly heterosexual population and the only trial to utilize a pox vector (ALVAC-HIV, vCP1521, canarypox vector) prime. The HVTN 505 regimen generated very little gp70V1V2 antibody, higher IgA, and very little IgG3 (G. Tomaras, personal communication).

\section{RV144: THE THAI PHASE III HIV-1 VACCINE TRIAL}

RV144 was conducted in 16,402 Thai men and women at mostly heterosexual "community risk" of HIV-1 (38). Volunteers received ALVAC-HIV (vCP1521) at months 0, 1, 3, and 6, and AIDSVAX ${ }^{\circledR} \mathrm{B} / \mathrm{E}$ at months 3 and 6 . ALVAC-HIV is a canarypox-based viral vector containing the Gag-Pro and gp41 transmembrane anchoring domain from the subtype B strain LAI and the gp120 Env from 92TH023, a CRF01_AE chronic virus. AIDSVAX ${ }^{\circledR} \mathrm{B} / \mathrm{E}$ is a bivalent vaccine containing the monomeric gp120s from the CCR5 tropic CRF01_AE strain CM244 (A244) and from subtype B MN.

HIV-1 incidence in the RV144 placebo group was 0.28 infections per 100 person-years, more than tenfold lower than that observed in Vax003, Vax004, Step, Phambili, or HVTN 505 (Table 1). Estimated VE at 42 months using the prespecified, modified intent-to-treat analysis was $31.2 \%$ (39). There were non-statistically significant differences in efficacy between men and women, but the study was not adequately powered to analyze subgroups. A post hoc analysis showed higher VE at 12 months $(60 \%)$ that decreased over time, consistent with decay in vaccine-induced immune responses (40). VE was higher among those whose initial self-reported risk was low and did not change during the trial. It was lower among those whose risk was not low at baseline and/or increased during the trial. Vaccination was not found to modify disease course; viral setpoint or postinfection CD4 counts, as well as time to CD4 count $\leq 350$ or AIDS-defining illness/death, were the same in both vaccine and placebo recipients (41). There was a statistically significant lowering of seminal fluid viral load in vaccine recipients who became infected, and although this finding has also been seen in NHPs, its impact is undefined (42). It was not known whether longer-term impact of vaccination on clinical progression might be seen, as was suggested in a NHP study (43).

Kim • Excler • Michael 


\section{ANALYSIS OF IMMUNE CORRELATES}

Nomenclature for the analysis of immune correlates in vaccine trials has recently been standardized $(15,44)$. Measured immune responses (or "biomarkers") from a vaccine trial are associated with the rate of a particular endpoint, such as HIV-1 infection in RV144. Statistically relevant responses are termed correlates of risk (CoR). A CoR may be a correlate of protection or simply mark pathogen exposure or genetic susceptibility to infection.

In Vax004, higher levels of NAb against $\mathrm{MN}$ and antibody-dependent cell-mediated viral inhibition were associated with lowered risk of infection $(45,46)$. The Step trial identified no CoR, although viruses infecting vaccine recipients, relative to placebo recipients, were more likely to contain specific sequences that diverged more from the vaccine insert. This suggests either a specific exclusion of insert-matched virus variants at the time of infectious challenge or postinfection modification and escape of founder viruses (or both). However, evidence of corresponding immune response was lacking, although evidence of cytotoxic lymphocyte pressure in vaccine recipients appeared broader than could be measured by interferon gamma (IFN- $\gamma$ ) Enzyme-Linked ImmunoSpot (ELISpot) assays.

In RV144 as well as the earlier ALVAC-HIV and AIDSVAX ${ }^{\circledR}$ B/E phase I/II trials $(39,47$, 48), the regimen induced binding antibody against HIV-1 Env immunogens and p24 Gag, CD4+ proliferative responses (63\%), some $\mathrm{CD}^{+}{ }^{+} \mathrm{T}$ cell responses $(24 \%)$, NAb against $\mathrm{T}$ cell line-adapted viruses of subtype B and CRF01_AE (96\% and 71\%, respectively), and antibody-dependent cellmediated cytotoxicity (ADCC).

Because it was difficult to a priori assign the "best" assays to a correlates analysis, an international collaboration initially performed a series of pilot studies to define "best in class" assays that were immunologically relevant but nonredundant, had reasonable dynamic range, and were reproducible. Once the assays were chosen, a prespecified analytical plan was approved, and the limited RV144 samples available at peak immunogenicity two weeks after the fourth vaccination were analyzed in a case-control study in $41 \mathrm{HIV}$-infected, vaccinated cases and 205 uninfected vaccinated controls to identify CoR (49). Two immune responses correlated with infection: (a) composite IgA binding to a set of 14 different HIV-1 envelopes directly correlated with infection, and (b) IgG binding to a gp70 V1V2 CaseA2 (subtype B) (50) scaffold inversely correlated with infection. IgA levels did not enhance infection but rather abrogated the protective effect of vaccination. IgG avidity, ADCC, NAb, and cellular immune responses did not appear to correlate with rate of HIV-1 infection. However, IgG avidity, ADCC, and NAb interacted with IgA (antigp70 V1V2 did not). In the setting of low anti-Env IgA, reduction in the risk of infection was seen for ADCC and $\mathrm{Nab}(51,52)$. Figure 1 summarizes the odds ratios (ORs) for the different correlates analyses performed on V2 (including gp70V1V2 Case A2) (53).

Though not all significant, these findings taken in aggregate show a striking pattern of $\mathrm{OR}<1$, again suggesting that binding to this critical Env domain may impact HIV-1 infection risk.

The choice of the V1V2 reagent was informed by preliminary data from analysis of RV144 binding antibody against linear epitopes in the HIV-1 envelope that showed multiple reactivities such as binding in the $\mathrm{V} 2$ region (including the $\alpha 4 \beta 7$ integrin binding site), as well as data suggesting that monoclonal antibodies $(\mathrm{mAb})$ recognizing conformational V2 blocked RV144 sera binding to gp120 (54). The linear epitope analysis included peptides from multiple subtypes, although there was limited binding to subtype B peptides in V2 $(49,51,52)$. The gp70 V1V2 CaseA2 reagent is the V1V2 region from a subtype B-infected individual attached to the murine leukemia virus gp70 protein (50), presenting the $\mathrm{V} 2$ region conformationally.

Viruses found after acquisition of HIV-1 in vaccine and placebo recipients were analyzed specifically in the Env V2 region to see whether there might be an association of particular viral

www.annualreviews.org • Lessons From RV144 HIV-1 Vaccine Trial
ADCC:

antibody-dependent cell-mediated cytotoxicity

mAb: monoclonal antibody

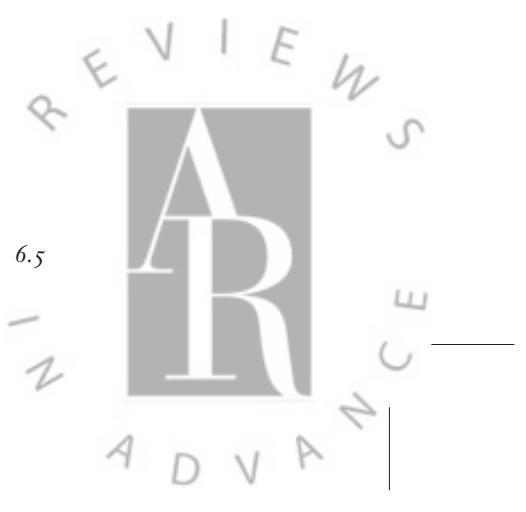




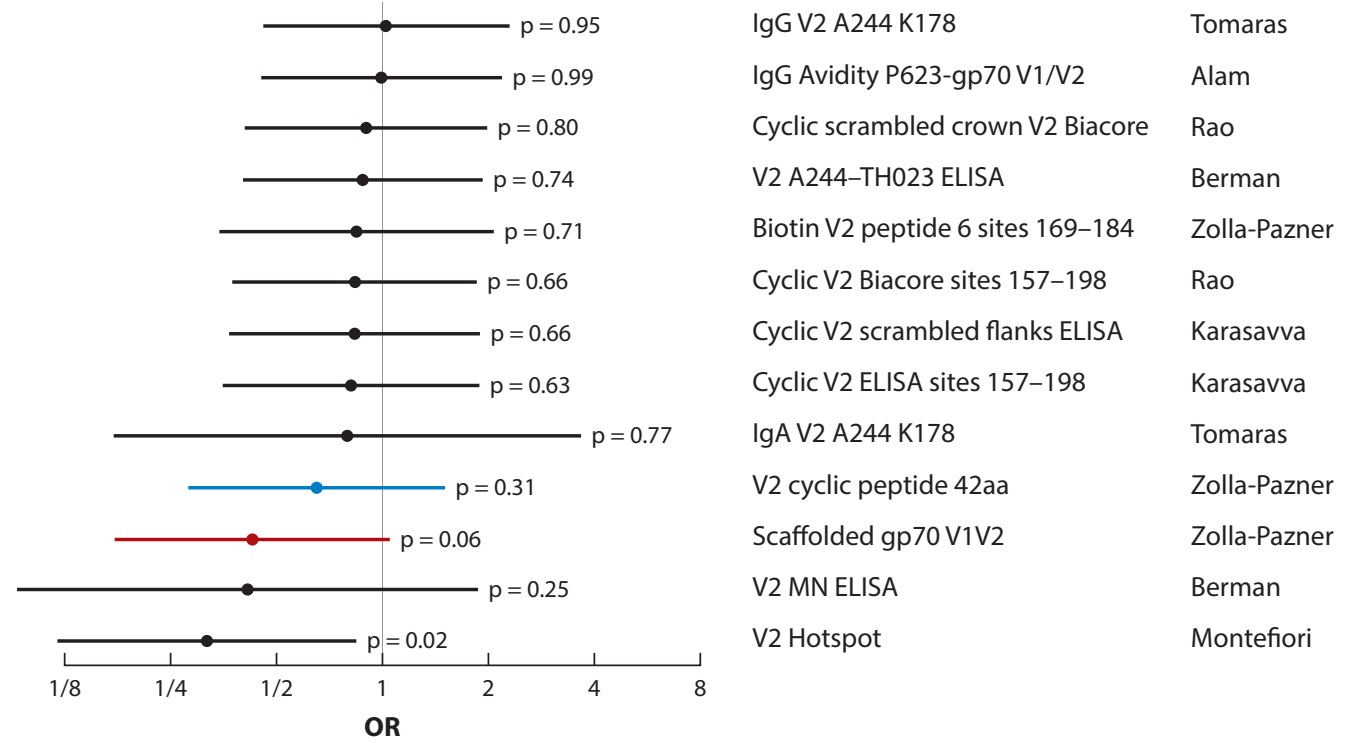

Figure 1

Estimated odds ratios (OR) and 95\% confidence intervals for various V2 assays performed in the RV144 analysis of the correlates of risk for HIV infection.

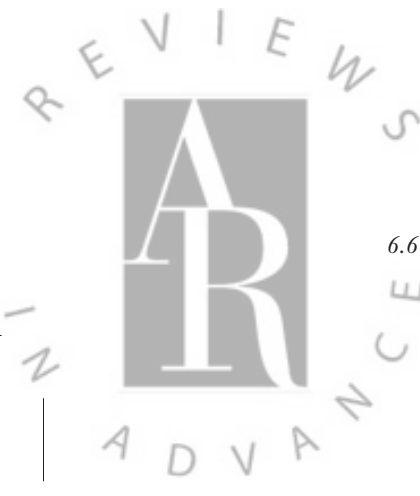

genotypes with receipt of vaccine, referred to as sieve analysis $(27,55-58)$. In RV144, HIV-1 strains that matched the vaccine sequence, containing a lysine at position 169 (K169) in the V2 domain of Env, appeared to be blocked by vaccination, as were viruses mismatched with vaccine at position 181. This result supports antibody directed at V2 being a CoR and further strengthens the original finding of efficacy in RV144. V2-specific binding antibody was found more commonly in RV144 vaccine recipients than in HIV-infected persons, was cross-reactive with V2 domains from other subtypes (59), and appeared to localize in the region defined by the sieve analysis (60). Monoclonal antibodies from RV144 vaccine recipients appeared to bind to a region of V2 that partially overlaps the binding of the bNAb CH01 and PG9, although the RV144 V2-specific mAbs are only weakly neutralizing. Scanning mutations of V2 show a critical contact between the CH58 and CH59 mAbs from RV144 and position 169 (one of the V2 sieve mutations). Though not broadly neutralizing, these V2-specific antibodies mediate ADCC. Further mapping of ADCC responses from RV144 volunteers shows that a significant portion of the immune responses is directed at the first constant region of gp120 Env (C1) (61). These C1-directed antibodies are able to block the binding of the $\mathrm{A} 32 \mathrm{mAb}$, which recognizes a conformational epitope that includes the $\mathrm{C} 1$ domain. The $\mathrm{C} 1$-specific antibodies appear to act synergistically with anti-V2 antibodies, possibly by inducing conformational changes that improve the exposure of V2 to binding (62).

Plasmas from RV144 vaccinees showed greater capacity for the capture of vaccine-strain viruses over transmitted/founder virus, although a variety of specificities (V2, C3, C1) were able to mediate viral aggregation/capture (63).

In the setting of lower Env-specific IgA, it was known that ADCC and nAb were inverse CoR (49). Looking at additional epitopes, however, there was evidence in the linear epitope analysis that antibody against the V3 crown was associated with reduced infection risk (52), and there is suggestive evidence from sieve analysis that two critical residues at 307 and 317 in the V3 crown may be associated with differential effects on vaccine efficacy (64).

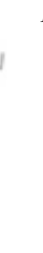

Changes may still occur before final publication online and in print 
Although the prespecified analysis of $\mathrm{CoR}$ did not detect a strong cellular signal associated with infection risk, a subsequent Bayesian analysis using a new computational tool, COMPASS, for the analysis of polyfunctionality of antigen-specific cellular immune responses revealed an inverse relationship between polyfunctionality score and HIV-1 infection (65). A five-function set comprising CD154, IL-2, IL-4, IFN $\gamma$, and TNF $\alpha$ showed the strongest correlation, and a three-function set (CD154, IL-2, and IL-4) was also inversely related to infection. The authors then proceeded to further evaluate COMPASS on other study sets, showing the versality of this analysis (CD154, IL2, and IL4) that demonstrated a similar but weaker relationship. COMPASS was also used to look at polyfunctionality and relevant outcomes in a study of tuberculosis in South African adolescents and showed improved sensitivity and specificity for the detection of tuberculosis infection compared to an IFN- $\gamma$ release assay.

\section{THE IGA DIRECT CORRELATE OF RISK}

Although IgA binding to Env was not enhancing, the ability of IgA to block the effect of vaccination could impact other vaccines/adjuvants. In several systems, IgA is known to interfere with IgG effector function (66), and further work with mAb from RV144 volunteers showed that IgA specific for the C1 region of HIV-1 Env could effectively block ADCC of HIV-1 infected cells (67). $\mathrm{IgA} / \mathrm{IgG}$ ratios were higher among infected vaccine recipients than among the uninfected. In addition, controlling statistically for the effect of IgA could unmask important additional CoR.

\section{RV144 CORRELATES OF RISK: PAST, PRESENT, AND FUTURE}

\section{RV144, Vax003, and Vax004}

RV144 raised an important question about the Vax003 trial using AIDSVAX ${ }^{\circledR}$ B/E, which did not show efficacy. The two efficacy trials differ in two important ways. Vax003 was conducted in IDUs. Systemic (e.g., intravenous injection) exposure bypasses the mucosal barriers to transmission and is often associated with the transmission of multiple strains (68), as opposed to the single transmitted virus found in most cases of heterosexual transmission. RV144 used an ALVAC-HIV prime and two AIDSVAX ${ }^{\circledR}$ B/E boosts, whereas Vax003 had an initial series of three injections of AIDSVAX ${ }^{\circledR} \mathrm{B} / \mathrm{E}$ followed by booster doses every 6 months. Vax003 recipients of two doses of AIDSVAX ${ }^{\circledR} \mathrm{B} / \mathrm{E}$ generated lower levels of NAb than RV144 recipients of two doses of AIDSVAX ${ }^{\circledR} \mathrm{B} / \mathrm{E}$, suggesting that the ALVAC-HIV vaccine prime augmented immune responses in RV144 vaccinees. However, after four doses of AIDSVAX ${ }^{\circledR} \mathrm{B} / \mathrm{E}$ in Vax003 vaccinees, NAb levels were higher than after the RV144 prime-boost regimen. IgG binding antibody responses were also higher after four doses of AIDSVAX ${ }^{\circledR} \mathrm{B} / \mathrm{E}$, but fractionation of Env- and V2-specific IgG subclasses showed statistically greater levels of IgG3 in RV144 vaccinees, and anti-V2 IgG3 was identified as an inverse CoR (69). IgG3 can fix complement, has a high affinity for the Fcy receptor, and has been associated with protection in several other infections (70, 71). The RV144 regimen elicited highly coordinated Fc-mediated effector responses, with the selective induction of highly functional IgG3 antibodies. By contrast, Vax003 elicited monofunctional antibody with a larger fraction of IgG4 selection. Moreover, only RV144 induced IgG1 and IgG3 antibodies targeting the crown of the HIV-1 envelope V2 loop, though with low coverage of breakthrough viral sequences (72). Together these data make an important point about the impact of the anticipated route of transmission (IDU versus heterosexual) on vaccine-related CoR and raise the possibility that the ALVAC-HIV prime responses may play a role in altering the quality of immune responses seen after protein inoculation (73).

www.annualreviews.org • Lessons From RV144 HIV-1 Vaccine Trial

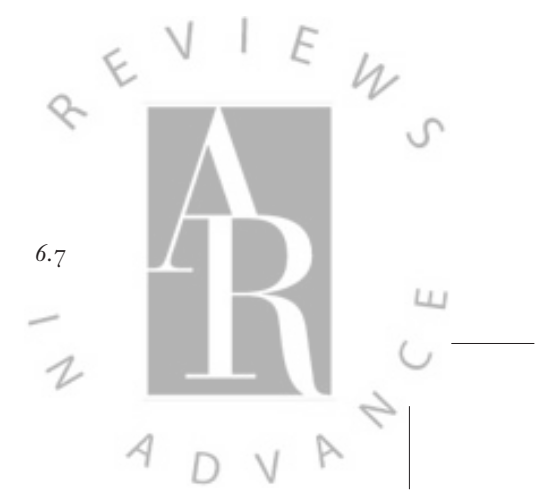


Vax004 was conducted in MSM with AIDSVAX ${ }^{\circledR}$ B/B. No efficacy was seen. Interestingly, analysis of anti-V2 binding to gp70 V1V2 shows important differences compared to RV144 (60). gp70 V1V2 Case A2 binding antibodies were substantially lower in Vax004 than in RV144. Given that levels of the anti-V1V2 antibody are higher in Vax003 than in RV144, this suggests that the two components of AIDSVAX ${ }^{\circledR} \mathrm{B} / \mathrm{B}$ may not generate antibody against the critical V1V2 antigen, and it strongly suggests that the key component in IIDSVAX $^{\circledR}$ B/E was the A244 CRF01_AE gp120 (i.e., that the $\mathrm{MN}$ gp120 component did not elicit anti-V2 responses). In previous clinical studies, monomeric gp120 induced high levels of Env-specific IgG4 antibodies (74) whereas ALVAC (vCP1452) prime and gp120 MN boost elicited lower IgG4 relative to IgG1 and IgG3 antibody levels (75). IgG4 antibodies have been associated with progression to AIDS (76). IgG4 antibodies were considerably lower in RV144 than in Vax003 (69). Why Env-specific IgG4 antibodies are induced in Vax003 and Vax004 and are less prominent in RV144 remains to be elucidated.

\section{Pox-Protein Follow-Up Studies}

Several studies are ongoing to examine the immunogenicity of ALVAC-HIV and AIDSVAX ${ }^{\circledR}$ $\mathrm{B} / \mathrm{E}$ in greater depth. In RV305, RV144 vaccine recipients are given two additional vaccinations ("late boosts") with ALVAC-HIV, AIDSVAX ${ }^{\circledR}$ B/E, or both. In RV306, naïve subjects receive the RV144 regimen followed by boosting at month 12 with ALVAC-HIV, AIDSVAX ${ }^{\circledR} \mathrm{B} / \mathrm{E}$, or both. RV328 is a small study of AIDSVAX ${ }^{\circledR} \mathrm{B} / \mathrm{E}$ vaccination (with a 12 -month boost) looking at B lymphoblasts and cellular immune responses. Mucosal collections (semen, cervicovaginal and rectal secretions, sigmoid and cervical biopsy tissue) and bone marrow aspirates are obtained. It is anticipated that licensure-track efficacy trials of ALVAC and gp120 prime-boost will occur in southern Africa and in Thailand. Efficacy testing of the vaccinia-derived NYVAC-based poxvirus with DNA and/or additional protein is being considered for southern Africa. These trials should start after 2015.

\section{RV144 CORRELATES AND IMMUNOGEN DESIGN}

In all AIDSVAX ${ }^{\circledR}$ gp120 antigens, the $\mathrm{N}$-terminal 11 amino acids are deleted and a Herpes simplex type 2 virus $\mathrm{gD}$ tag is added to facilitate purification. With the increased focus on anti-V2 antibody, Alam and colleagues (54) looked carefully at the antigenic conformation of the gp120 immunogens found in $\mathrm{AIDSVAX}^{\circledR} \mathrm{B} / \mathrm{E}$. Using a series of mAbs that recognize conformational $\mathrm{C} 1, \mathrm{~V} 2, \mathrm{~V} 3$, and V2V3 epitopes, they found that gp120 A244 had remarkable exposure of the V2 domain, a property conferred by the N-terminal deletion (54) and not by Herpes simplex virus type $2 \mathrm{gD}$. Interestingly, the deletion of $\mathrm{N}$-terminal sequences does not uniformly improve either antigenicity or immunogenicity. New immunogens containing these deletions and screened for antigenicity in comparison to A244 are being made and tested (14).

\section{LESSONS LEARNED}

\section{The Importance of Empirical Vaccine Trials}

In the context of efficacy trials to show protection from $\mathrm{HIV}-1$ acquisition, the $\mathrm{VE}$ of $31.2 \%$ in RV144 makes several points. An HIV-1 vaccine that did not generate bNAb may, in community-risk populations, reduce the risk of HIV-1 infection. A similar pattern of protection against acquisition with "Tier 1" NAb is seen in the Ad26/MVA (modified vaccinia Ankara) SIV challenge studies (77), and similar limited neutralization in the face of "partial" protection in 
the animal model is seen with ALVAC-SIV and SIV gp120 (78). In the absence of a validated animal model or known correlates of protection, empirical vaccine trials remain critical as proofs-of-concept and generate new testable hypotheses. The RV144 result, the subsequent identification of $\mathrm{CoR}$, and the characterization of sieve mutations provide a mutually supportive argument for the initial demonstration of efficacy and insight into its potential mechanisms.

\section{The Limitations of Correlates of Risk}

Though helpful, the CoR identified in RV144 should not be considered canonical and continue to generate hypotheses. The large number of tests and the small number of samples tested precluded the use of the more stringent Bonferroni correction for multiplicity. Critically, these CoR analyses are driving the design of new immunogens, the development of new schedules, and the search for more potent adjuvants to build on and improve the efficacy seen in RV144. Furthermore, CoR identified using the RV144 regimen may not predict CoR or efficacy using different vaccine vectors, primes, or boosts, although it is interesting that NHP challenge studies with an MVA-SIV and Ad26-SIV prime-boost regimen showed $(37,77,79)$ that envelope is critical to protection and that antibodies to Env, specifically $\mathrm{V} 2$, are correlates of protection.

\section{UNANSWERED QUESTIONS}

Why does vaccine-induced antibody to the V2 variable region of gp120 Env correlate inversely with infection risk? The V2 loop appears to play a role in the critical transmission step of HIV-1 pathogenesis (80). It forms a part of the CCR5 coreceptor-binding domain $(81,82)$ and contains a putative $\alpha 4 \beta 7$ mucosal-homing integrin binding site (83). A subset of very potent bNAb recognizes a V2V3 quaternary determinant (84-86). These antibodies, though overlapping in V2 binding with RV144-associated mAb, have substantially greater neutralizing capacity and highly mutated the VDJ (variable, diverse, joining) gene segments of the heavy chains of immunoglobulins and extended CDR3 regions (87). Interestingly, one of the two gp120 Envs in AIDSVAX $^{\circledR}$ B/E binds to all these reagents and to the putative germline sequences (84) from which a subset of this V2V3 bNAb derives.

Are there non-neutralizing antibodies that mediate protection from acquisition? Given that the reported neutralization using the RV144 regimen is weak $(48,51)$ and assuming that CD8mediated viral control is also minimal $(48,49)$, is there a mechanism for the $60 \%$ efficacy seen at 12 months that decreased to $31 \%$ at 42 months? Supporting a role for antibody is the evidence of genetic sieving of viral sequences—sites that correspond to the binding of mAb from RV144 volunteers. Antibody-dependent cell-mediated viral inhibition had been identified as a potential CoR in the VaxGen trials (45). It was difficult to measure in RV144, but ADCC in RV144 appeared robust, and much of it was C1 directed $(47,61)$. When stratified for anti-Env IgA, ADCC was also inversely correlated with acquisition. This raises the question of how an essentially cellular mechanism of viral control could effect control of acquisition, if not in the mucosal tissues.

Although RV144 showed protection from HIV-1 acquisition, the generation of bNAb by vaccination remains an important goal. While binding to the germline $\mathrm{B}$ cell receptor (BCR) variable regions sequences of V2/V3 bNAb is seen with a limited number of gp120s and gp140s (84), it is difficult to demonstrate binding to germline BCR V genes for CD4-binding-site $\mathrm{bNAb}$ (88). Binding of immunogens to germline $\mathrm{B}$ cell receptor and directed evolution of vaccineinduced antibodies represent one approach that may yield vaccine-induced bNAb $(14,89)$.

What did the ALVAC-HIV prime do? ALVAC-HIV did not induce substantial antibody and $\mathrm{CD}^{+}$or $\mathrm{CD}^{+} \mathrm{T}$ cell activity $(48,90)$. It did appear that after the RV144 regimen NAb were

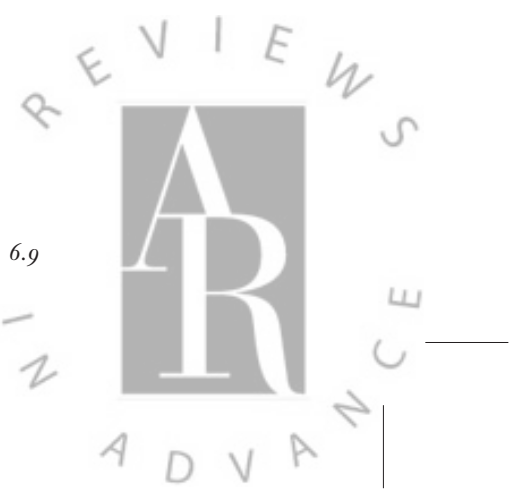


greater than after two doses of AIDSVAX ${ }^{\circledR}$ B/E alone (51). Linear epitope mapping of plasmas from RV144 and Vax003 suggest the presence of additional epitopes in Vax003, perhaps a shift to IgG3 antibodies, intimating a role for ALVAC-HIV in shaping the antibody repertoire of the subsequent boosts (52). Little is known about the susceptibility of ALVAC-vector-specific CD4 ${ }^{+}$ T cells to HIV-1 infection.

What role do cellular immune responses play? Cellular immune responses in phase II and IIb studies of ALVAC-HIV (vCP1521) and AIDSVAX ${ }^{\circledR}$ B/E do not show the CD8 ${ }^{+}$effector memory T cells to be important for vaccine-mediated, postinfection control of viremia $(39,48,49,77,79$, 91). Although $\mathrm{CD}^{+}{ }^{+}$responses are clearly induced by the $\mathrm{RV} 144$ regimen (39), the contribution of these responses to the observed efficacy is unknown, and $\mathrm{CD}^{+} \mathrm{T}$ cell responses are clearly aided by the addition of a protein boost (92). Interestingly, part of the $\mathrm{CD}^{+}{ }^{+} \mathrm{T}$ cell response is directed at the V2 loop, and phenotypically the cells express CD107a (functional marker of natural killer cell activity) and are cytolytic, although the impact of such cells on infection is, again, unknown (93). The newer COMPASS analysis suggests that a subset of cellular, antigen-specific responses might be associated with reduced infection risk but requires prospective validation in future animal or human studies (65).

How do IgA anti-Env responses factor into the future evaluation of vaccine candidates? In the RV144 correlates analysis, monomeric Env-specific plasma IgA correlated directly with risk of infection and interacted with all other humoral primary analyses except for IgG against V2 avidity, NAb, and ADCC (49). Monomeric plasma IgA appears to inhibit the binding of IgG, which mediates ADCC (67). Whether this is a function of one or both of the immunogens, the adjuvant, or the vaccination schedule is unknown. Monomeric plasma IgA antibodies do not cross the mucosal barrier. We do not know whether secretory IgA antibodies were induced in the mucosal secretions, as these specimens were not collected in RV144 but are being collected in RV305 and RV306.

Many of the questions raised would benefit from a relevant and validated NHP or humanized mouse model enabling the testing of putative CoR, and significantly informing ongoing translational and clinical research. Several NHP studies support the RV144 findings. ALVAC-SIV and SIV gp120 conferred a modest protective effect (30\%) from low-dose intrarectal SIVmac251 challenge (78). This protective effect was correlated with higher avidity of gp120-specific antibody that recognized the $\mathrm{V} 2$ variable envelope region and reduced SIVmac251 infectivity in cells expressing high level of $\alpha 4 \beta 7$, suggesting a functional role of V2 antibodies. Availability of different subtype CRF01_AE simian-human immunodeficiency virus (SHIV) constructs for NHP challenge studies would also be useful to directly test the anti-V1V2 IgG CoR to HIV-1 envelope, by infusing these mAbs into NHP and performing a relevant SHIV challenge. Attempts to generate such SHIVs are under way in two independent laboratories.

Similarly, the use of humanized bone marrow/liver/thymus (BLT) or HLA-DR4 expressing (DRAG) mice could be an important step forward. The ability of DRAG mice to produce human IgG subclasses (and IgA) could be of particular interest as new monomeric and/or trimeric Env vaccine candidates are developed. Both mouse systems can be infected via intrarectal or intravaginal inoculation, so it is conceivable that low-dose mucosal-challenge systems could be used for work on $\mathrm{CoR}$, mechanistic correlates of protection, or preclinical evaluation of efficacy (94-96).

\section{CONCLUSION}

RV144 was the first HIV-1 vaccine trial to demonstrate efficacy against HIV-1 infection. The detailed analysis of immune CoR showed that IgG antibodies directed against a scaffolded V1V2

Kim • Excler • Michael 
region of gp120 seem to play a predominant role in protection against HIV-1 acquisition and that plasma Env IgA antibodies were directly correlated with risk, although their respective mechanistic roles remain to be demonstrated. Put in perspective, RV144 and recent NHP challenge studies suggest that Env is essential and perhaps sufficient to induce protective antibody responses against HIV-1 acquisition at the mucosal entry. Follow-up clinical trials have started to provide further insight into the peripheral as well as mucosal immune responses. The RV144 correlates work inspired improvements in Env immunogens, for which preclinical data should soon be available. Whether the immune CoR identified in RV144 can be extended to other populations with different modes and intensity of transmission remains to be demonstrated. Efficacy trials are now planned in heterosexual populations in southern Africa and MSM in Thailand.

\section{DISCLOSURE STATEMENT}

The authors are not aware of any affiliations, memberships, funding, or financial holdings that might be perceived as affecting the objectivity of this review.

\section{ACKNOWLEDGMENTS}

We are grateful to all clinical trial participants. We thank the Thai AIDS Vaccine Evaluation Group and the Thailand Ministry of Public Health, as well as all scientists who contributed to the RV144 analysis of the immune correlates of risk for their dedication and leadership. This study was supported in part by Interagency Agreement Y1-AI-2642-12 between US Army Medical Research and Material Command (USAMRMC) and the National Institutes of Allergy and Infectious Diseases, and by a cooperative agreement (W81XWH-07-2-0067) between the Henry M. Jackson Foundation for the Advancement of Military Medicine, Inc., and the US Department of Defense. The opinions expressed herein are those of the authors and should not be construed as official or representing the views of the US Department of the Army or Department of Defense.

\section{LITERATURE CITED}

1. UNAIDS. 2013. Report on the global AIDS epidemic. http://www.unaids.org/en/media/unaids/ contentassets/documents/epidemiology/2013/gr2013/unaids_global_report_2013_en.pdf

2. Nitayaphan S, Ngauy V, O'Connell R, et al. 2012. HIV epidemic in Asia: optimizing and expanding vaccine development. Expert Rev. Vaccines 11:805-19

3. Abdool Karim Q, Abdool Karim SS, Frohlich JA, et al. 2010. Effectiveness and safety of tenofovir gel, an antiretroviral microbicide, for the prevention of HIV infection in women. Science 329:1168-74

4. Grant RM, Lama JR, Anderson PL, et al. 2010. Preexposure chemoprophylaxis for HIV prevention in men who have sex with men. N. Engl. F. Med. 363:2587-99

5. Baeten JM, Donnell D, Ndase P, et al. 2012. Antiretroviral prophylaxis for HIV prevention in heterosexual men and women. N. Engl. F. Med. 367:399-410

6. Choopanya K, Martin M, Suntharasamai P, et al. 2013. Antiretroviral prophylaxis for HIV infection in injecting drug users in Bangkok, Thailand (the Bangkok Tenofovir Study): a randomised, double-blind, placebo-controlled phase 3 trial. Lancet 381:2083-90

7. Van Damme L, Corneli A, Ahmed K, et al. 2012. Preexposure prophylaxis for HIV infection among African women. N. Engl. F. Med. 367:411-22

8. Fauci AS, Marston HD. 2014. Ending AIDS-Is an HIV vaccine necessary? N. Engl. F. Med. 370:495-98

9. Haynes BF, McElrath MJ. 2013. Progress in HIV-1 vaccine development. Curr. Opin. HIV AIDS 8:32632

10. Hemelaar J, Gouws E, Ghys PD, et al. 2011. Global trends in molecular epidemiology of HIV-1 during 2000-2007. AIDS 25:679-89

www.annualreviews.org • Lessons From RV144 HIV-1 Vaccine Trial

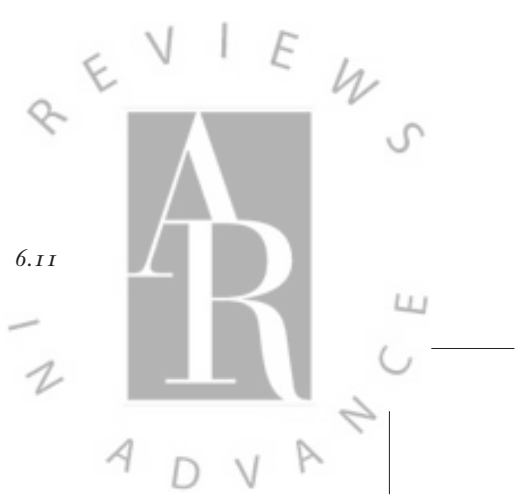


11. McBurney SP, Ross TM. 2008. Viral sequence diversity: challenges for AIDS vaccine designs. Expert Rev. Vaccines 7:1405-17

12. Moir S, Chun TW, Fauci AS. 2011. Pathogenic mechanisms of HIV disease. Annu. Rev. Pathol. 6:223-48

13. Burton DR, Ahmed R, Barouch DH, et al. 2012. A blueprint for HIV vaccine discovery. Cell Host Microbe 12:396-407

14. Haynes BF, Kelsoe G, Harrison SC, et al. 2012. B-cell-lineage immunogen design in vaccine development with HIV-1 as a case study. Nat. Biotechnol. 30:423-33

15. Plotkin SA, Gilbert PB. 2012. Nomenclature for immune correlates of protection after vaccination. Clin. Infect. Dis. 54:1615-17

16. Plotkin SA. 2013. Complex correlates of protection after vaccination. Clin. Infect. Dis. 56:1458-65

17. Mascola JR. 2007. HIV/AIDS: allied responses. Nature 449:29-30

18. Burton DR, Hessell AJ, Keele BF, et al. 2011. Limited or no protection by weakly or nonneutralizing antibodies against vaginal SHIV challenge of macaques compared with a strongly neutralizing antibody. Proc. Natl. Acad. Sci. USA 108:11181-86

19. Blankson JN. 2011. The study of elite controllers: a pure academic exercise or a potential pathway to an HIV-1 vaccine? Curr. Opin. HIV AIDS 6:147-50

20. Berman PW, Gregory TJ, Riddle L, et al. 1990. Protection of chimpanzees from infection by HIV-1 after vaccination with recombinant glycoprotein gp120 but not gp160. Nature 345:622-25

21. Girard M, Kieny MP, Pinter A, et al. 1991. Immunization of chimpanzees confers protection against challenge with human immunodeficiency virus. Proc. Natl. Acad. Sci. USA 88:542-46

22. Flynn NM, Forthal DN, Harro CD, et al. 2005. Placebo-controlled phase 3 trial of a recombinant glycoprotein 120 vaccine to prevent HIV-1 infection. F. Infect. Dis. 191:654-65

23. Gilbert PB, Peterson ML, Follmann D, et al. 2005. Correlation between immunologic responses to a recombinant glycoprotein 120 vaccine and incidence of HIV-1 infection in a phase $3 \mathrm{HIV}-1$ preventive vaccine trial. F. Infect. Dis. 191:666-77

24. Pitisuttithum P, Gilbert P, Gurwith M, et al. 2006. Randomized, double-blind, placebo-controlled efficacy trial of a bivalent recombinant glycoprotein $120 \mathrm{HIV}-1$ vaccine among injection drug users in Bangkok, Thailand. F. Infect. Dis. 194:1661-71

25. Buchbinder SP, Mehrotra DV, Duerr A, et al. 2008. Efficacy assessment of a cell-mediated immunity HIV-1 vaccine (the Step Study): a double-blind, randomised, placebo-controlled, test-of-concept trial. Lancet 372:1881-93

26. McElrath MJ, De Rosa SC, Moodie Z, et al. 2008. HIV-1 vaccine-induced immunity in the test-ofconcept Step Study: a case-cohort analysis. Lancet 372:1894-905

27. Rolland M, Tovanabutra S, deCamp AC, et al. 2011. Genetic impact of vaccination on breakthrough HIV-1 sequences from the STEP trial. Nat. Med. 17:366-71

28. Fitzgerald DW, Janes H, Robertson M, et al. 2011. An Ad5-vectored HIV-1 vaccine elicits cell-mediated immunity but does not affect disease progression in HIV-1-infected male subjects: results from a randomized placebo-controlled trial (the Step study). F. Infect. Dis. 203:765-72

29. Li F, Finnefrock AC, Dubey SA, et al. 2011. Mapping HIV-1 vaccine induced T-cell responses: bias towards less-conserved regions and potential impact on vaccine efficacy in the Step study. PLOS ONE 6:e20479

30. Gray GE, Allen M, Moodie Z, et al. 2011. Safety and efficacy of the HVTN 503/Phambili study of a clade-B-based HIV-1 vaccine in South Africa: a double-blind, randomised, placebo-controlled test-ofconcept phase 2b study. Lancet Infect. Dis. 11:507-15

31. Duerr A, Huang Y, Buchbinder S, et al. 2012. Extended follow-up confirms early vaccine-enhanced risk of HIV acquisition and demonstrates waning effect over time among participants in a randomized trial of recombinant adenovirus HIV vaccine (Step Study). F. Infect. Dis. 206:258-66

32. Gray GE, Moodie Z, Metch B, et al. 2014. Recombinant adenovirus type $5 \mathrm{HIV}$ gag/pol/nef vaccine in South Africa: unblinded, long-term follow-up of the phase $2 \mathrm{~b}$ HVTN 503/Phambili study. Lancet Infect. Dis. 14:388-96

33. Reynolds MR, Weiler AM, Piaskowski SM, et al. 2012. A trivalent recombinant Ad5 gag/pol/nef vaccine fails to protect rhesus macaques from infection or control virus replication after a limiting-dose heterologous SIV challenge. Vaccine 30:4465-75

Kim • Excler • Michael 
34. Qureshi H, Ma ZM, Huang Y, et al. 2012. Low-dose penile SIVmac251 exposure of rhesus macaques infected with adenovirus type 5 (Ad5) and then immunized with a replication-defective Ad5-based SIV $\mathrm{gag} / \mathrm{pol} / \mathrm{nef}$ vaccine recapitulates the results of the phase IIb step trial of a similar HIV-1 vaccine. 7. Virol. $86: 2239-50$

35. Hammer SM, Sobieszczyk ME, Janes H, et al. 2013. Efficacy trial of a DNA/rAd5 HIV-1 preventive vaccine. N. Engl. F. Med. 369:2083-92

36. Letvin NL, Rao SS, Montefiori DC, et al. 2011. Immune and genetic correlates of vaccine protection against mucosal infection by SIV in monkeys. Sci. Transl. Med. 3:81ra36

37. Roederer M, Keele BF, Schmidt SD, et al. 2014. Immunological and virological mechanisms of vaccinemediated protection against SIV and HIV. Nature 505:502-8

38. Ministry of Public Health-Thai AIDS Vaccine Evaluation Group. 2011. Screening and evaluation of potential volunteers for a phase III trial in Thailand of a candidate preventive HIV vaccine (RV148). Vaccine 29:4285-92

39. Rerks-Ngarm S, Pitisuttithum P, Nitayaphan S, et al. 2009. Vaccination with ALVAC and AIDSVAX to prevent HIV-1 infection in Thailand. N. Engl. F. Med. 361:2209-20

40. Robb ML, Rerks-Ngarm S, Nitayaphan S, et al. 2012. Risk behaviour and time as covariates for efficacy of the HIV vaccine regimen ALVAC-HIV (vCP1521) and AIDSVAX B/E: a post-hoc analysis of the Thai phase 3 efficacy trial RV 144. Lancet Infect. Dis. 12:531-37

41. Rerks-Ngarm S, Paris RM, Chunsutthiwat S, et al. 2013. Extended evaluation of the virologic, immunologic, and clinical course of volunteers who acquired HIV-1 infection in a phase III vaccine trial of ALVAC-HIV and AIDSVAX B/E. F. Infect. Dis. 207:1195-205

42. Whitney JB, Luedemann C, Hraber P, et al. 2009. T-cell vaccination reduces simian immunodeficiency virus levels in semen. 7. Virol. 83:10840-43

43. Letvin NL, Mascola JR, Sun Y, et al. 2006. Preserved CD4+ central memory T cells and survival in vaccinated SIV-challenged monkeys. Science 312:1530-33

44. Plotkin SA. 2008. Vaccines: correlates of vaccine-induced immunity. Clin. Infect. Dis. 47:401-9

45. Forthal DN, Gilbert PB, Landucci G, et al. 2007. Recombinant gp120 vaccine-induced antibodies inhibit clinical strains of HIV-1 in the presence of Fc receptor-bearing effector cells and correlate inversely with HIV infection rate. F. Immunol. 178:6596-603

46. Gilbert P, Wang M, Wrin T, et al. 2010. Magnitude and breadth of a nonprotective neutralizing antibody response in an efficacy trial of a candidate HIV-1 gp120 vaccine. F. Infect. Dis. 202:595-605

47. Karnasuta C, Paris RM, Cox JH, et al. 2005. Antibody-dependent cell-mediated cytotoxic responses in participants enrolled in a phase I/II ALVAC-HIV/AIDSVAX B/E prime-boost HIV-1 vaccine trial in Thailand. Vaccine 23:2522-29

48. Nitayaphan S, Pitisuttithum P, Karnasuta C, et al. 2004. Safety and immunogenicity of an HIV subtype $\mathrm{B}$ and $\mathrm{E}$ prime-boost vaccine combination in HIV-negative Thai adults. F. Infect. Dis. 190:702-6

49. Haynes BF, Gilbert PB, McElrath MJ, et al. 2012. Immune-correlates analysis of an HIV-1 vaccine efficacy trial. N. Engl. 7. Med. 366:1275-86

50. Pinter A, Honnen WJ, Kayman SC, et al. 1998. Potent neutralization of primary HIV-1 isolates by antibodies directed against epitopes present in the V1/V2 domain of HIV-1 gp120. Vaccine 16:1803-11

51. Montefiori DC, Karnasuta C, Huang Y, et al. 2012. Magnitude and breadth of the neutralizing antibody response in the RV144 and Vax003 HIV-1 vaccine efficacy trials. F. Infect. Dis. 206:431-41

52. Gottardo R, Bailer RT, Korber BT, et al. 2013. Plasma IgG to linear epitopes in the V2 and V3 regions of HIV-1 gp120 correlate with a reduced risk of infection in the RV144 vaccine efficacy trial. PLOS ONE 8:e75665

53. Zolla-Pazner S, deCamp AC, Cardozo T, et al. 2013. Analysis of V2 antibody responses induced in vaccinees in the ALVAC/AIDSVAX HIV-1 vaccine efficacy trial. PLOS ONE 8:e53629

54. Alam SM, Liao HX, Tomaras GD, et al. 2013. Antigenicity and immunogenicity of RV144 vaccine AIDSVAX clade E envelope immunogen is enhanced by a gp120 N-terminal deletion. F. Virol. 87:155468

55. Berman PW, Gray AM, Wrin T, et al. 1997. Genetic and immunologic characterization of viruses infecting MN-rgp120-vaccinated volunteers. F. Infect. Dis. 176:384-97

www.annualreviews.org • Lessons From RV144 HIV-1 Vaccine Trial




56. Gilbert PB. 2001. Interpretability and robustness of sieve analysis models for assessing HIV strain variations in vaccine efficacy. Stat. Med. 20:263-79

57. Gilbert PB, Wu C, Jobes DV. 2008. Genome scanning tests for comparing amino acid sequences between groups. Biometrics 64:198-207

58. Rolland M, Edlefsen PT, Larsen BB, et al. 2012. Increased HIV-1 vaccine efficacy against viruses with genetic signatures in Env V2. Nature 490:417-20

59. Zolla-Pazner S, Decamp A, Gilbert PB, et al. 2014. Vaccine-induced IgG antibodies to V1V2 regions of multiple HIV-1 subtypes correlate with decreased risk of HIV-1 infection. PLOS ONE 9:e87572

60. Karasavvas N, Billings E, Rao M, et al. 2012. The Thai phase III HIV type 1 vaccine trial (RV144) regimen induces antibodies that target conserved regions within the V2 loop of gp120. AIDS Res. Hum. Retroviruses 28:1444-57

61. Bonsignori M, Pollara J, Moody MA, et al. 2012. Antibody-dependent cellular cytotoxicity-mediating antibodies from an HIV-1 vaccine efficacy trial target multiple epitopes and preferentially use the VH1 gene family. F. Virol. 86:11521-32

62. Pollara J, Bonsignori M, Moody MA, et al. 2014. HIV-1 vaccine-induced C1 and V2 Env-specific antibodies synergize for increased antiviral activities. F. Virol. 88:7715-26

63. Liu P, Yates NL, Shen X, et al. 2013. Infectious virion capture by HIV-1 gp120-specific IgG from RV144 vaccinees. F. Virol. 87:7828-36

64. Rolland MEP, Gottardo R, et al. 2013. Genetic and immunological evidence for a role of Env-V3 antibodies in the RV144 trial. Abstr. P03.73 LB. In Proc. AIDS Vaccine 2013, Barcelona, Spain

65. Brusic V, Gottardo R, Kleinstein SH, et al. 2014. Computational resources for high-dimensional immune analysis from the Human Immunology Project Consortium. Nat. Biotechnol. 32:146-48

66. Griffiss JM, Goroff DK. 1983. IgA blocks IgM and IgG-initiated immune lysis by separate molecular mechanisms. F. Immunol. 130:2882-85

67. Tomaras GD, Ferrari G, Shen X, et al. 2013. Vaccine-induced plasma IgA specific for the C1 region of the HIV-1 envelope blocks binding and effector function of IgG. Proc. Natl. Acad. Sci. USA 110:9019-24

68. Bar KJ, Li H, Chamberland A, et al. 2010. Wide variation in the multiplicity of HIV-1 infection among injection drug users. F. Virol. 84:6241-47

69. Yates NL, Liao HX, Fong Y, et al. 2014. Vaccine-induced Env V1-V2 IgG3 correlates with lower HIV-1 infection risk and declines soon after vaccination. Sci. Transl. Med. 6:228ra39

70. Roussilhon C, Oeuvray C, Muller-Graf C, et al. 2007. Long-term clinical protection from falciparum malaria is strongly associated with IgG3 antibodies to merozoite surface protein 3. PLOS Med. 4:e320

71. Kam YW, Simarmata D, Chow A, et al. 2012. Early appearance of neutralizing immunoglobulin G3 antibodies is associated with chikungunya virus clearance and long-term clinical protection. F. Infect. Dis. 205:1147-54

72. Chung AW, Ghebremichael M, Robinson H, et al. 2014. Polyfunctional Fc-effector profiles mediated by IgG subclass selection distinguish RV144 and VAX003 vaccines. Sci. Transl. Med. 6:228ra38

73. Teigler JE, Phogat S, Franchini G, et al. 2014. The canarypox virus vector ALVAC induces distinct cytokine responses compared to the vaccinia virus-based vectors MVA and NYVAC in rhesus monkeys. 7. Virol. 88:1809-14

74. Gorse GJ, Patel GB, Mandava M, et al. 1999. MN and IIIB recombinant glycoprotein 120 vaccineinduced binding antibodies to native envelope glycoprotein of human immunodeficiency virus type 1 primary isolates. National Institute of Allergy and Infectious Disease AIDS Vaccine Evaluation Group. AIDS Res. Hum. Retroviruses 15:921-30

75. Banerjee K, Klasse PJ, Sanders RW, et al. 2010. IgG subclass profiles in infected HIV type 1 controllers and chronic progressors and in uninfected recipients of Env vaccines. AIDS Res. Hum. Retroviruses 26:445-58

76. Ljunggren K, Broliden PA, Morfeldt-Manson L, et al. 1988. IgG subclass response to HIV in relation to antibody-dependent cellular cytotoxicity at different clinical stages. Clin. Exp. Immunol. 73:343-47



77. Barouch DH, Liu J, Li H, et al. 2012. Vaccine protection against acquisition of neutralization-resistant SIV challenges in rhesus monkeys. Nature 482:89-93

Kim • Excler • Michael 
78. Pegu P, Vaccari M, Gordon S, et al. 2013. Antibodies with high avidity to the gp120 envelope protein in protection from simian immunodeficiency virus SIV(mac251) acquisition in an immunization regimen that mimics the RV-144 Thai trial. F. Virol. 87:1708-19

79. Barouch DH, Stephenson KE, Borducchi EN, et al. 2013. Protective efficacy of a global HIV-1 mosaic vaccine against heterologous SHIV challenges in rhesus monkeys. Cell 155:531-39

80. Sagar M, Wu X, Lee S, et al. 2006. Human immunodeficiency virus type 1 V1-V2 envelope loop sequences expand and add glycosylation sites over the course of infection, and these modifications affect antibody neutralization sensitivity. F. Virol. 80:9586-98

81. Kwong PD, Wyatt R, Robinson J, et al. 1998. Structure of an HIV gp120 envelope glycoprotein in complex with the CD4 receptor and a neutralizing human antibody. Nature 393:648-59

82. Rizzuto CD, Wyatt R, Hernandez-Ramos N, et al. 1998. A conserved HIV gp120 glycoprotein structure involved in chemokine receptor binding. Science 280:1949-53

83. Arthos J, Cicala C, Martinelli E, et al. 2008. HIV-1 envelope protein binds to and signals through integrin alpha4beta7, the gut mucosal homing receptor for peripheral T cells. Nat. Immunol. 9:301-9

84. Bonsignori M, Hwang KK, Chen X, et al. 2011. Analysis of a clonal lineage of HIV-1 envelope V2/V3 conformational epitope-specific broadly neutralizing antibodies and their inferred unmutated common ancestors. F. Virol. 85:9998-10009

85. Pejchal R, Doores KJ, Walker LM, et al. 2011. A potent and broad neutralizing antibody recognizes and penetrates the HIV glycan shield. Science 334:1097-103

86. Walker LM, Phogat SK, Chan-Hui PY, et al. 2009. Broad and potent neutralizing antibodies from an African donor reveal a new HIV-1 vaccine target. Science 326:285-89

87. Benjelloun F, Lawrence P, Verrier B, et al. 2012. Role of human immunodeficiency virus type 1 envelope structure in the induction of broadly neutralizing antibodies. F. Virol. 86:13152-63

88. Hoot S, McGuire AT, Cohen KW, et al. 2013. Recombinant HIV envelope proteins fail to engage germline versions of anti-CD4bs bNAbs. PLOS Pathog. 9:e1003106

89. Burton DR, Poignard P, Stanfield RL, et al. 2012. Broadly neutralizing antibodies present new prospects to counter highly antigenically diverse viruses. Science 337:183-86

90. Thongcharoen P, Suriyanon V, Paris RM, et al. 2007. A phase $1 / 2$ comparative vaccine trial of the safety and immunogenicity of a CRF01_AE (subtype E) candidate vaccine: ALVAC-HIV (vCP1521) prime with oligomeric gp160 (92TH023/LAI-DID) or bivalent gp120 (CM235/SF2) boost. F. Acquir. Immune Defic. Syndr. 46:48-55

91. Hansen SG, Vieville C, Whizin N, et al. 2009. Effector memory T cell responses are associated with protection of rhesus monkeys from mucosal simian immunodeficiency virus challenge. Nat. Med. 15:29399

92. Ratto-Kim S, Loomis-Price LD, Aronson N, et al. 2003. Comparison between env-specific T-cell epitopic responses in HIV-1-uninfected adults immunized with combination of ALVAC-HIV(vCP205) plus or minus rgp160MN/LAI-2 and HIV-1-infected adults. F. Acquir. Immune Defic. Syndr. 32:9-17

93. de Souza MS, Ratto-Kim S, Chuenarom W, et al. 2012. The Thai phase III trial (RV144) vaccine regimen induces $\mathrm{T}$ cell responses that preferentially target epitopes within the V2 region of $\mathrm{HIV}-1$ envelope. 7. Immunol. 188:5166-76

94. Brehm MA, Shultz LD, Luban J, et al. 2013. Overcoming current limitations in humanized mouse research. F. Infect. Dis. 208(Suppl. 2):S125-30

95. Danner R, Chaudhari SN, Rosenberger J, et al. 2011. Expression of HLA class II molecules in humanized NOD.Rag1KO.IL2RgcKO mice is critical for development and function of human T and B cells. PLOS ONE 6:e19826

96. Allam AF. 2014. Characterization of B-and T cells in the gut mucosa of humanized DRAG mice during HIV infection. Presented at Keystone Symp. HIV Vaccines-Adaptive Immunity and Beyond, Banff, Alberta, Can. 